\title{
An Animal Model of Hypersensitivity Pneumonitis in the Rabbit
}

\author{
Vernon L. Moore, George T. Hensley, and Jordan N. Fink \\ From the Allergy Section, Department of Medicine, The Medical College of \\ Wisconsin and the Research Service, Wood Veterans Administration Center, \\ Milwaukee, Wisconsin 53193, and Department of Pathology, University of \\ Miami School of Medicine, Miami, Florida 33124
}

A B S T R A C T This study was devised to produce an animal model of hypersensitivity pneumonitis in order to study both the induction and the elicitation of the disease. Rabbits exposed by aerosol to large quantities of pigeon antigens developed a humoral, but not cellular, immunologic response. Moreover, their lungs were essentially normal histologically. A single i.v. injection of killed BCG in oil permitted the induction of pulmonary cell-mediated hypersensitivity to the inhaled antigen, as well as the development of pulmonary lesions which were more severe than that caused by the administration of BCG alone. The humoral immunologic response to the inhaled antigen was not increased after $\mathrm{BCG}$ injection. Since many individuals are exposed to the etiologic agents of hypersensitivity pneumonitis for extended periods without developing the disease, these findings in animals suggest that some event may occur to induce cell-mediated hypersensitivity in order to initiate the disease process.

In addition, we have shown that animals with normal lung histology and circulating complement-fixing antibodies undergo serum complement $\left(\mathrm{CH}_{50}\right)$ depression after an aerosol challenge with the specific antigen. Animals with circulating, complement-fixing antibodies, and inflamed lungs (BCG-induced) failed to undergo a complement depression subsequent to an aerosol challenge with specific antigens. These results are consistent with those seen in symptomatic and asymptomatic pigeon breeders and suggest that antigen distribution through the lung is important in the pathogenesis of hypersensitivity pneumonitis.

Preliminary reports of this research were presented at the 11th National Meeting of the Reticuloendothelial Society, 4 December 1974, Seattle, Wash., and at the Annual Meeting of the American Academy of Allergy, San Diego, Calif., 16 February 1975.

Received for publication 21 March 1975 and in revised form 9 June 1975.

\section{INTRODUCTION}

Hypersensitivity pneumonitis is an allergic lung disorder characterized by fever, chills, and dyspnea in its acute phase (1), the presence of serum precipitating antibodies to the implicated antigens (2), and cell-mediated hypersensitivity $(\mathrm{CMH})^{1}$ in at least one of these disorders (3-5). These diseases are presumably due to the continued or intermittent inhalation of a wide variety of organic dusts (6), i.e., the route of antigen exposure that leads to a hypersensitivity state is through the respiratory tract.

The incidence of disease in human subjects exposed to similar "antigenic loads" for long periods of time is $6-10 \%$ (3). In addition, it has been demonstrated that both symptomatic and asymptomatic pigeon breeders develop functionally similar circulating antibodies to pigeon antigens $(7,8$, unpublished data). These findings suggest that other factor(s) are involved in the induction of the disease in addition to the inhalation of antigens with subsequent antibody synthesis.

Recently we observed that asymptomatic pigeon breeders displayed a serum complement $\left(\mathrm{CH}_{50}\right)$ depression subsequent to an aerosol challenge with pigeon serum, while symptomatic breeders did not exhibit such a serum complement depression after similar challenge (4). Interestingly, both groups have serum precipitating, complement-fixing antibodies to pigeon serum antigens $(4,7)$. Furthermore, we observed that peripheral leukocytes from the symptomatic group produced migration inhibition factor $(s)$ (MIF) in vitro when challenged with pigeon antigens; leukocytes from asymptomatic breeders did not produce these factors (4). These findings have suggested that cellular immune mechanisms

\footnotetext{
${ }^{1}$ Abbreviations used in this paper: $\mathrm{CMH}$, cell-mediated hypersensitivity; H\&E, hematoxylin and eosin; MIF, migration inhibition factor; $\mathrm{PDE}$, pigeon dropping extract; $\mathrm{T}$ cell, thymus-derived lymphocyte.
} 
may be important in the pathogenesis of hypersensitivity pmeumonitis and that complement-fixing antibodies could function in the removal of the inhaled antigens (6).

One possible event responsible for the induction of hypersensitivity pneumonitis could be the exposure of the individual to an agent capable of activating thymusderived ( $\mathrm{T}$ )-cell immunity to inhaled organic antigens, e.g., infections with viral, fungal, or bacterial intracellular parasites. The present study in rabbits was therefore designed to: $(a)$ study the induction of hypersensitivity pneumonitis by antigen inhalation in combination with an agent known to activate $\mathrm{T}$ cells and $(b)$ test some of the events in the experimental animal model that we have observed in human studies (4).

\section{METHODS}

Antigen. A pigeon dropping extract (PDE) was prepared by extracting dried pigeon droppings with 10 vol of $0.01 \mathrm{M}$ phosphate-buffered saline $(0.15 \mathrm{M} \mathrm{NaCl}), \mathrm{pH}$ 7.4 for 1 wk at $4^{\circ} \mathrm{C}$. This material was filtered through $4 \times 8$ gauze and stored at $-20^{\circ} \mathrm{C}$ until used for insufflation. For immunologic studies, PDE was dialyzed for 1 wk in large volumes of distilled water at $4^{\circ} \mathrm{C}$. The material was then lyophilized and stored at $-20^{\circ} \mathrm{C}$ until used.

Insuffation procedures. The animals were placed in an airtight box containing an inlet and an exhaust. An ultrasonic nebulizer (model 900, DeVilbiss Co., Medical Products Div., Somerset, Pa.) was connected to the inlet by means of a flexible hose. The exhaust was passed into a flask containing water by means of another flexible hose to prevent contamination of the surrounding environment. The antigen solution (PDE) was placed in the nebulizer, and 35-50 ml were insufflated into the box over a 1-h period.

Animals. Outbred New Zealand rabbits weighing 1.5$3.0 \mathrm{~kg}$ were used. They were maintained in the laboratory animal facility of the Research Service, Veterans Administration Center, Wood (Milwaukee), Wis.

Experimental protocol. Animals were divided into five groups (Table I).

Group I. These animals were subjected to an aerosol challenge of $\mathrm{PDE}$ on 5 consecutive days per wk for 3-4 mo. Inhalation exposure was terminated when serum precipitins to PDE were detectable by immunodiffusion.

Group IIa. After aerosol exposure to PDE for 3-4 mo when the animals had detectable serum precipitating antibodies to PDE, this group of animals was injected i.v. with $100 \mu \mathrm{g}$ of a killed lyophilized strain of Mycobacterium bovis (BCG) ${ }^{2}$ suspended in light mineral oil (Marcol 52, Humble Oil \& Refining Co., Houston, Tex.). The procedure for the preparation of this reagent has been described (9). The animals were again insufflated daily with PDE for another 3-4 wk and their lung histology evaluated $6 \mathrm{~h}$ after the last exposure to PDE.

Group IIb. These animals were exposed similarly, as in Group IIa, except that their lung histology was assessed $24 \mathrm{~h}$ subsequent to the last exposure to PDE.

Group III. Five rabbits were injected i.v. with $100 \mu \mathrm{g}$ of killed BCG in oil and evaluated 3 wk later.

GROUP IV. This group is composed of five normal rabbits.

${ }^{2}$ Generously supplied by Ms. Eva S. Leake.
All groups of animals were evaluated for the parameters listed in Table I.

Immunologic studics. Passive hemagglutination was performed as described by Campbell et al. (10) and was used to measure relative amounts of total antibody activity. Tanned cell hemolysis was carried out by the method described by Block et al. (11) to determine relative amounts of complement-fixing antibodies in the sera of the groups of animals. In both of these techniques, $2 \mathrm{mg}$ of $\mathrm{PDE} / \mathrm{ml}$ was used to coat tanned sheep erythrocytes. The results of antibody activity titers are expressed as the geometric mean and $95 \%$ confidence limits for each group of animals. Precipitins were determined by a standard two-dimensional agar gel immunodiffusion method (11). $\mathrm{CMH}$ in cells from the lung was assessed by the migration inhibitory technique $(9,12)$. The cells collected from the lung were challenged in vitro with $250 \mu \mathrm{g}$ of $\mathrm{PDE} / \mathrm{ml}$, or $250 \mu \mathrm{g}$ of $\mathrm{PDE} / \mathrm{ml}$ plus $5 \mu \mathrm{g}$ of puromycin $-\mathrm{HCl} / \mathrm{ml}$. Puromycin was used to ensure that antigen-induced inhibitory activity was not merely a result of immobilization of macrophages due to the toxicity of PDE. It is known that puromycin inhibits the synthesis of MIF (13) and should therefore reverse antigen-induced inhibition of migration. The tissue culture medium employed was TC-199 supplemented with $20 \%$ fetal bovine serum (Grand Island Biological Co., Grand Island, N. Y.), $100 \mathrm{U}$ of penicillin G/ml, $100 \mu \mathrm{g}$ of streptomycin sulfate $/ \mathrm{ml}$, and $0.2 \mathrm{mM} \mathrm{L}$-glutamine, final $\mathrm{pH} 7.0$. The cells were allowed to migrate out of $1.2-\mathrm{mm}$ capillary tubes onto glass surfaces for $24 \mathrm{~h}$. They were magnified about 10 times and the areas quantified by planimetry. Areas of migration are expressed as the arithmetic mean $\pm 95 \%$ confidence, and differences were evaluated by Student's $t$ test.

Complement. Complement activity $\left(\mathrm{CH}_{50}\right)$ on rabbit sera was quantified by a method described by our laboratory (14).

Histology. Lungs were removed and inflated with buffered, $6.0 \%$ glutaraldehyde and prepared for routine hematoxylin and eosin (H\&E) sections. These preparations were evaluated independently by the pathologist (G. T. H.) without prior knowledge of the procedure carried out on the animals.

Statistics. These calculations are described by Lutz (15).

\section{RESULTS}

The results of these studies are summarized in Table I.

\section{Lung histology}

Group I. The lungs of these rabbits, which had been exposed to PDE by inhalation for 3 mo and whose serum contained antibodies to PDE, were essentially normal with respect to bronchial and alveolar anatomy (Fig. 1).

Group IIa. Examination of the lungs of these animals $6 \mathrm{~h}$ after the last exposure to PDE showed severe, acute, exudative pneumonitis. The inflammatory reac.tion had a definite lobular distribution and often showed focal suppuration (Fig. 2a). Occasional epithelial ulceration was found. No bacteria were identified with special stains, and lung cultures were sterile. A higherpower magnification (Fig. $2 b$ ) revealed that most of the 
TABLE I

Summary of Observation

\begin{tabular}{|c|c|c|c|c|c|c|c|}
\hline \multirow[b]{2}{*}{ Group } & \multirow[b]{2}{*}{ Exposure } & \multicolumn{3}{|c|}{$\begin{array}{l}\text { Serum antibody response } \\
\text { to PDE }\end{array}$} & \multirow{2}{*}{$\begin{array}{c}\text { Complement } \\
\text { change after } \\
\text { aerosol } \\
\text { challenge }\end{array}$} & \multirow{2}{*}{$\begin{array}{l}\text { CMH to } \\
\text { PDE }\end{array}$} & \multirow[b]{2}{*}{ Lung histology (no. examined) } \\
\hline & & $\mathrm{TCH}$ & PHA & Ppt & & & \\
\hline I & PDE aerosol & + & + & + & Depression & No & Normal (6) \\
\hline I Ia & PDE aerosol, BCG, PDE aerosol ( $+6 \mathrm{~h})$ & + & + & + & No change & ND & Chronic \& acute inflammation (5) \\
\hline IIb & PDE aerosol, BCG, PDE aerosol $(+24 \mathrm{~h})$ & + & + & + & No change & Yes & Mostly chronic inflammation (4) \\
\hline III & BCG & - & - & - & ND & No & Chronic inflammation (2) \\
\hline IV & None & - & - & - & Elevation & ND & Normal (2) \\
\hline
\end{tabular}

ND, not done; PHA, passive hemagglutination; Ppt, precipitins; TCH, tanned cell hemolysis.

cells of the exudate were polymorphonuclear leukocytes. These lesions were usually most intense in and around BCG-induced granulomas, but were readily distinguishable from BCG control animals (group III) (Fig. 4) which lacked an acute inflammatory reaction.

Group IIb. This group, examined $24 \mathrm{~h}$ after the last aerosol exposure to PDE, showed a striking recovery from the acute exudative reaction seen at $6 \mathrm{~h}$ post-

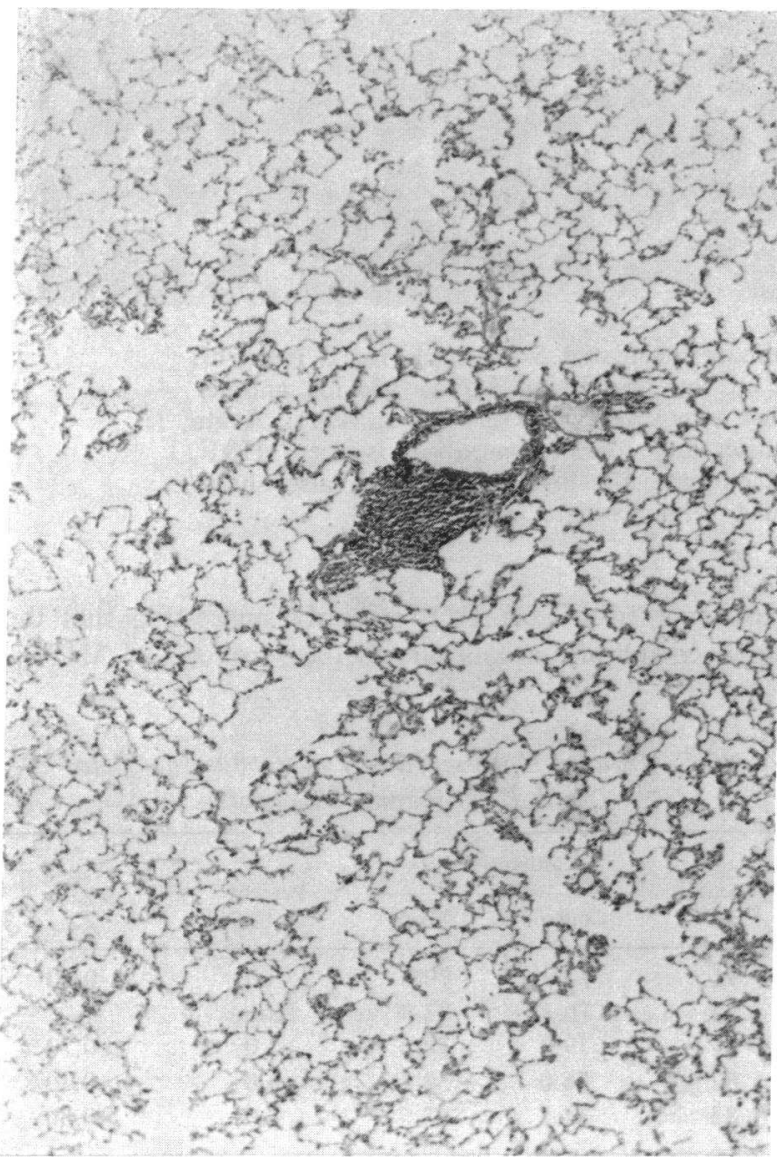

FIGURE 1 Scan view of lung from animals insufflated 5 days/wk for 3 mo with PDE (group I). Normal alveolar and bronchial structure is seen. $\mathrm{H} \& \mathrm{E}, \times 24$. challenge (Figs. $3 a$ and $b$ ), but the number of alveolar macrophages in the same areas was increased above those found in the BCG control group (group III) (Fig. 4). In addition, the nuclei of the alveolar macrophages seen in this group were relatively hyperchromatic.

Group III. This control group (given only BCG) had pulmonary lesions typical of those induced by i.v. injected adjuvant (16). In addition to large nodular infiltrations composed of lymphocytes and macrophages (Fig. 4), small widely separated groups of alveoli were present that contained prominent alveolar macrophages. There was no evidence of the acute inflammation which was noted in the experimental group (group II).

Group IV (normal rabbits). No photographs are shown but they are essentially as seen in Fig. 1.

\section{Antibody activity}

Animals exposed to an aerosol challenge of $\mathrm{PDE}$ for 3 mo (group I) produced moderate titers of hemagglutinating antibodies; these titers were not significantly changed when the animals were injected with BCG followed by continued insufflation with PDE (group II) (Table II). Similarly, complement-fixing antibody activity, as assessed by tanned cell hemolysis, was not significantly different in these two groups (Table II). Antibody activity of PDE could not be detected in nor-

TABLE II

Antibody Activity in Group $I^{*}$ and II $\ddagger$ Rabbits

\begin{tabular}{lcc}
\hline & Group I & Group II \\
\hline Passive hemagglutination & $274[194,388] \S(5) \|$ & $416[294,588](5)$ \\
& $0.50>P>0.40$ \\
Tanned cell hemolysis & $734[286,1,885](5)$ & $556[155,1,992](5)$ \\
& $0.70>P>0.60$
\end{tabular}

* Subjected to an aerosol challenge with PDE 5 days/wk for 3 mo. ¥ Subjected to an aerosol challenge with PDE 5 days/wk for $3 \mathrm{mo}$, injected i.v. with $200 \mu \mathrm{g}$ of killed BCG in oil, and subjected to an aerosol challenge with PDE 5 days/wk for 3 wk.

\& Geometric mean and $95 \%$ confidence limits.

\| Number of animals.

Experimental Hypersensitivity Pneumonitis 939 


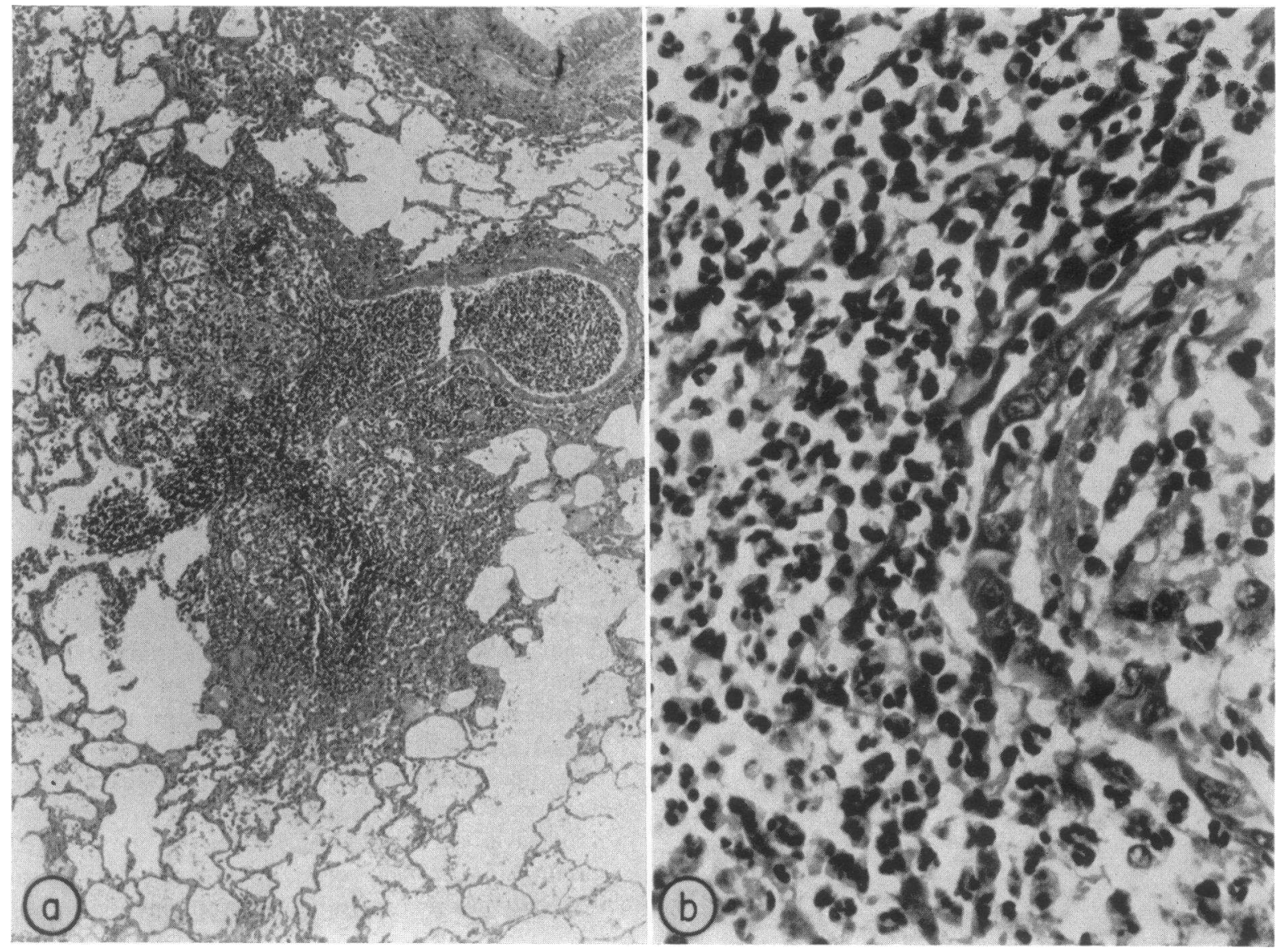

FIGURE 2 (a) Low-power view of lung from animals insufflated 5 days/wk for 3 mo with PDE and given $100 \mu \mathrm{g}$ of killed BCG i.v. and PDE by insufflation 5 days/wk for another 3 wk. The animals were killed $6 h$ after the last exposure to PDE (group IIa). Acute exudative bronchopneumonia with lobular distribution and focal suppuration is seen. H\&E, $\times 60$. (b) Higher-power view of Fig. $2 a$. Purulent exudate fills bronchiole, which also shows ulceration of epithelium. Adjacent alveoli are filled with exudate. H\&E, $\times 144$.

mal rabbits or in those injected only with BCG (Table I).

\section{CMH ( Tables III and IV)}

$\mathrm{CMH}$ to PDE was not detectable in cells recovered from the lungs of rabbits insufflated with that antigen for 3 mo (group I) (Table III). However, an i.v. injection of BCG in conjunction with continued aerosol exposure to PDE resulted in the induction of $\mathrm{CMH}$ in the lung to PDE (Table IV). Since there was a possibility that PDE immobilized the lung macrophages directly rather than stimulating sensitized lymphocytes, some reactions were carried out in the presence of PDE as well as puromycin, an inhibitor of MIF biosynthesis (13). In these tests the inhibition caused by PDE alone was reversed (Table IV), strongly suggesting that the observed inhibition was due to the synthesis of MIF.

TABLE III

Cell-Mediated Hypersensitivity in Rabbits Insufflated with PDE (Group I Animals)

\begin{tabular}{ccccc}
\hline \multirow{2}{*}{$\begin{array}{c}\text { Animal } \\
\text { no. }\end{array}$} & Control & Test* & $\begin{array}{c}\text { Percent } \\
\text { inhibition }\end{array}$ & $P \ddagger$ \\
\cline { 2 - 5 } & Clanimetry units & P & \\
\hline 91 & 77.28 & 70.5 & 9.0 & $>0.10$ \\
92 & 76.3 & 83.3 & None & - \\
81 & 79.7 & 78.0 & 2.0 & $>0.70$ \\
82 & 56.0 & 52.7 & 6.0 & $>0.40$ \\
83 & 74.1 & 68.5 & 8.0 & $>0.30$ \\
\hline
\end{tabular}

* Challenged in vitro with $250 \mu \mathrm{g}$ of $\mathrm{PDE} / \mathrm{ml}$.

I Student's $t$ test.

$\S$ Mean of at least six determinations per animal. 


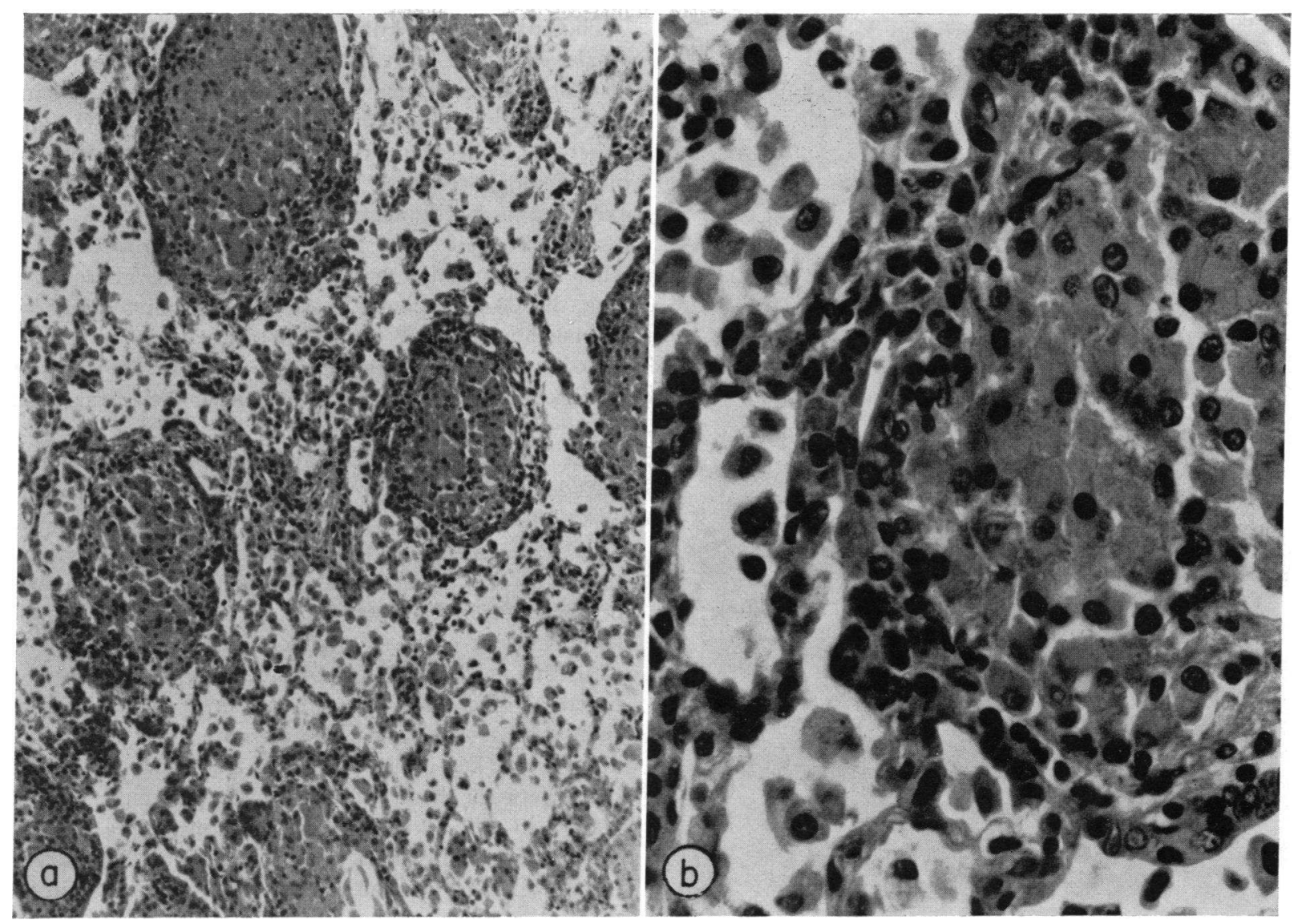

FIGURE 3 (a) Low-power view of lung from animals insufflated 5 days/wk for 3 mo with $\mathrm{PDE}$ and given $100 \mu \mathrm{g}$ of killed BCG i.v. and PDE by insufflation 5 days/wk for another 3 wk. The animals were killed $24 h$ after the last exposure to PDE (group IIb). BCGinduced granulomas are prominent and alveolar spaces contain increased numbers of cells. $\mathrm{H} \& \mathrm{E}, \times 60$. (b) Higher-power of Fig. $3 a$ showing that the cells in the alveolar spaces are macrophages rather than granulocytes. H\&E, $\times 240$.

TABLE IV

Cell-Mediated Hypersensitivity in Rabbits Insuffated with $P D E$ and Given $B C G^{*}$

\begin{tabular}{|c|c|c|c|c|c|}
\hline \multirow{2}{*}{$\begin{array}{c}\text { Animal } \\
\text { no. }\end{array}$} & \multicolumn{3}{|c|}{ Planimetry units } & \multirow{2}{*}{$\begin{array}{c}\text { Percent } \\
\text { inhibition }\end{array}$} & \multirow[b]{2}{*}{$P \ddagger$} \\
\hline & Control & Test! & $+\mathrm{Pm} \delta$ & & \\
\hline 90 & $52.6 \|$ & 22.0 & 45.0 & 58 & $<0.05$ \\
\hline 86 & 71.8 & 31.3 & 67.6 & 56 & $<0.05$ \\
\hline 93 & 82.3 & 36.2 & 76.8 & 56 & $<0.05$ \\
\hline 94 & 72.5 & 40.7 & 75.0 & 44 & $<0.05$ \\
\hline 95 & 56.3 & 23.0 & 56.5 & 59 & $<0.05$ \\
\hline
\end{tabular}

* $100 \mu \mathrm{g}$ of killed BCG i.v. in $0.1 \mathrm{ml}$ of a light mineral oil (Marcol 52).

† Challenged in vitro with $250 \mu \mathrm{g}$ of $\mathrm{PDE} / \mathrm{ml}$

$\S$ Challenged in vitro with $250 \mu \mathrm{g}$ of $\mathrm{PDE} / \mathrm{ml}+5 \mu \mathrm{g}$ of puromycin- $\mathrm{HCl} / \mathrm{ml}$.

$\ddagger$ Student's $t$ test.

\|Mean of at least six determinations per animal.

\section{Serum complement activity (Fig. 5)}

Depressions, significant at 4 and $8 \mathrm{~h}$, in serum complement activity $\left(\mathrm{CH}_{80}\right)$ after an aerosol challenge with PDE were seen only in group I animals. Normal rabbits did not undergo a serum complement depression after a single aerosol challenge with PDE; in fact, there was a significant increase at 8 and $24 \mathrm{~h}$ postinsufflation. Group II animals did not show serum complement depressions after a single aerosol challenge with PDE, despite the presence of serum complementfixing antibodies (Fig. 5). These animals did not, however, show an increase in serum complement activity as was observed in normal rabbits.

\section{DISCUSSION}

This study has shown that it is possible to produce an animal model of hypersensitivity pneumonitis in which events similar to those observed in human cases of

Experimental Hypersensitivity Pneumonitis 


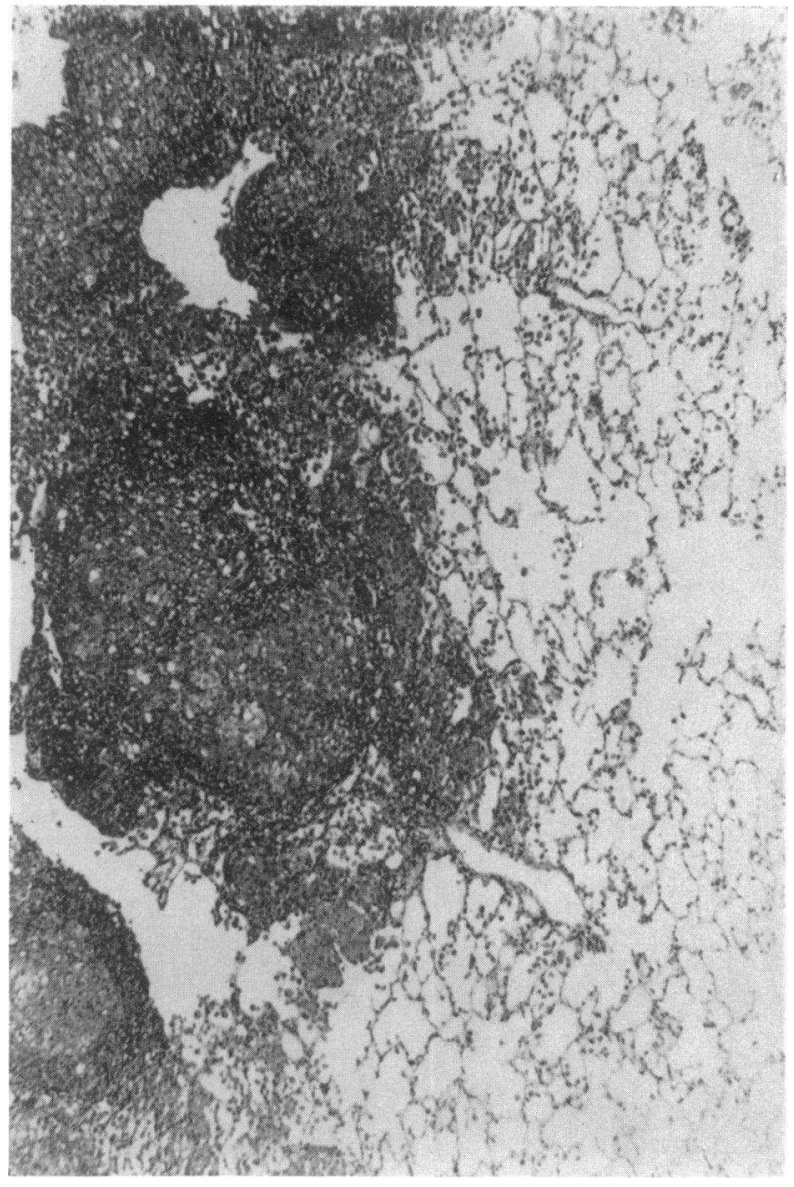

FIGURE 4 Animals injected i.v. a single time with $100 \mu \mathrm{g}$ of killed BCG in oil and evaluated 3 wk later. BCG-induced granulomas are prominent and alveolar spaces contain increased numbers of cells. $\mathrm{H} \& \mathrm{E}, \times 60$.

pigeon breeder's disease occur (4). In addition, the results presented here suggest that hypersensitivity pneumonitis may occur after an alteration in pulmonary tissue with some agent which allows the induction of $\mathrm{CMH}$ in the lung to an inhaled soluble antigen.

The normal histological appearance of the lungs of animals exposed to PDE for 3 mo (group I), as well as a negative $\mathrm{CMH}$ reaction in the lung, suggests that inhalation per se with PDE is insufficient to cause lung damage or to induce $\mathrm{CMH}$ in the lung. The immunologic event that is observed is the appearance of serum antibodies, albeit of moderate activity, to the inhaled antigen. Presumably, this is the experimental animal counterpart of asymptomatic human subjects who have been exposed for long periods of time to aerosols of organic antigens. It is noteworthy that these individuals develop predominately a humoral antibody response, and show little or no pulmonary function abnormalities upon aerosol exposure to the antigen to which they have developed antibodies (4).
The injection of killed BCG followed by continued inhalation of PDE resulted in marked changes in the histological appearance of rabbit lungs that were distinctively different from animals injected with $\mathrm{BCG}$ alone. Whereas, BCG alone caused a chronic granulomatous inflammatory response (group III), group II animals exhibited a florid acute inflammatory response when examined $6 \mathrm{~h}$ after the last aerosol challenge with PDE. This acute reaction had largely subsided at $24 \mathrm{~h}$. In fact, the 24-h response in group IIb animals was not remarkably different from that observed in animals injected with BCG alone. Despite the histological similarities in group IIb and III animals, there was a significant functional difference in the cells inside these lungs, because group IIb animals exhibited $\mathrm{CMH}$ in their lungs to PDE.

A major question concerns the immunologic mechanism responsible for the acute inflammatory response seen in group IIa animals. The temporal appearance of this reaction is consistent with both an immune complex lesion and an early reaction of $\mathrm{CMH}$. One cannot explain this reaction simply by differences in amounts or functions of circulating antibody, since the antibody responses of group I and II animals were not significantly different. A key issue may be the differences in $\operatorname{IgE}$ activity between these two groups, since immune complex disease in rabbit kidneys requires a preceding "anaphylactic trigger" involving $\operatorname{IgE}(17)$. In preliminary results, we have been unable to detect $\operatorname{IgE}$ activity by passive cutaneous anaphylaxis in either group I or II

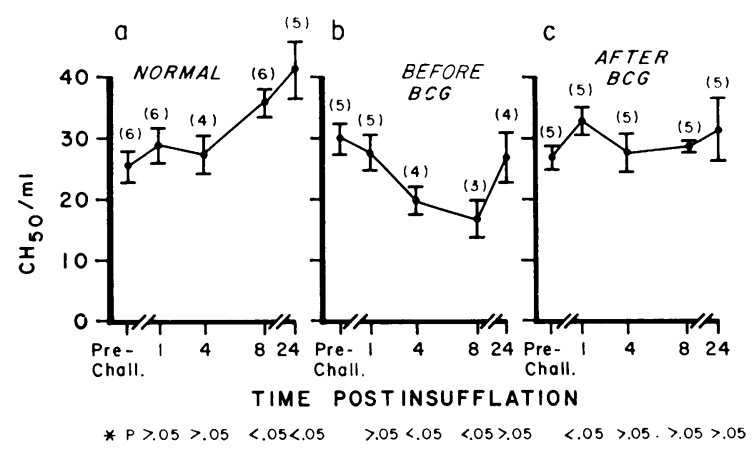

FIgURE 5 Serum complement $\left(\mathrm{CH}_{50}\right)$ changes in rabbits after an aerosol challenge with PDE. (a) Normal rabbits. (b) Before BCG rabbits were insufflated 5 days/wk with PDE for 3 mo (group I). 3 days later the changes in serum $\mathrm{CH}_{50}$ values were noted after an aerosol challenge with PDE. (c) After BCG rabbits were insufflated 5 days/wk with PDE for $3 \mathrm{mo}$, given $100 \mu \mathrm{g}$ of killed BCG in oil i.v., and again insufflated 5 days/wk with PDE for 3 wk. 3 days after the last insufflation the changes in serum $\mathrm{CH}_{50}$ values were noted after an aerosol challenge with PDE. Values are mean \pm SEM. The number of determinations is in parentheses. * Prechallenge vs. postchallenge, Student's $t$ test. 
animals. ${ }^{3}$ If immune complex disease in rabbit lungs requires a preceding "anaphylactic trigger," these preliminary results would suggest that the acute inflammatory response seen in group IIa animals is an early $\mathrm{CMH}$ reaction.

The correlation between the lesions observed here and in human cases of hypersensitivity pneumonitis is not clear. The usual findings in lung biopsies of patients with hypersensitivity pneumonitis is a chronic granulomatous inflammatory response $(18,19)$. However, recent studies in patients with farmer's lung have revealed the presence of acute inflammation, particularly during symptomatic episodes $(20,21)$. It is therefore possible that many acute responses in hypersensitivity pneumonitis associated with fever, chills, and dyspnea are provoked by an acute inflammatory response in the lung.

A unique finding in the present study was that the induction of a chronic inflammatory response in the lung with BCG, coincident with the inhalation of a soluble antigen, permits the induction of $\mathrm{CMH}$ to the inhaled antigen. This observation would seem to be consistent with that reported by Miller et al. (22) that immunopotentiation with BCG is possible when the unrelated antigen and BCG are deposited in the same tissue. Activation of $\mathrm{T}$-cell responses in hypersensitivity pneumonitis can explain several events. Firstly, patients with disease usually have much higher titers of circulating antibodies $(4,23,24)$. This can be explained by the production of helper $\mathrm{T}$ cells, assuming that the antigens involved are $\mathrm{T}$-dependent. In addition, several laboratories have reported that $\mathrm{T}$-cell activity to pigeon antigens, the etiologic agents of pigeon breeder's disease, are detected chiefly in symptomatic patients and not in their asymptomatic but similarly exposed counterparts (3-5). This might suggest that some type of an inflammatory process occurred in the lungs of patients with hypersensitivity pneumonitis which allowed the activation of $\mathrm{T}$ cells to the inhaled antigen. Lastly, the symptoms of hypersensitivity pneumonitis in man can largely be explained by assuming that the disease is caused by a systemic $\mathrm{CMH}$ reaction (25).

Other data presented here show that serum complement activity is depressed after an aerosol challenge with antigen only in rabbits with normal lung histology and circulating complement-fixing antibody. Complement depressions after an aerosol challenge were not observed in normal rabbits or in rabibts with circulating complement-fixing antibody plus inflamed lungs. These results are consistent with those observed in symptomatic and asymptomatic pigeon breeders (4) and have helped us formulate a hypothesis about antigen distribution after an aerosol challenge in hypersensitivity pneumonitis.

\footnotetext{
${ }^{3}$ Moore, V. L. Unpublished observations.
}

We have suggested that the chronic inflammatory process that is seen in patients with hypersensitivity lung disease somehow impedes the flow of antigen through the lung so that little or no antigen is permitted access to the circulation (4). This "trapping" process could conceivably be due to an increase in the number of phagocytic cells or to local antibody production in the lung. By similar reasoning, antigens could traverse "normal" lungs into the circulation, form antigen-antibody complexes, and lead to serum complement depressions. Such a hypothesis would predict that more antigen-antibody complexes could be detected after an aerosol challenge in animals with normal lungs and with serum complement-fixing antibodies.

In conclusion, an animal model of hypersensitivity pneumonitis has been produced. Exposure by aerosol to an antigen involved in pigeon breeder's disease in itself failed to produce lung disease. However, the production of a chronic inflammatory response in animals previously exposed by aerosol to BCG produced severe inflammatory reactions in rabbit lungs accompanied by the induction of $\mathrm{CMH}$ in the lung to the inhaled antigen. Serum antibody titers were not significantly increased after injection with BCG. Changes in serum complement levels similar to those seen in symptomatic and asymptomatic pigeon breeders have been observed. These findings may help us explain the events that occur in the lung subsequent to an aerosol challenge. In addition, this animal model will enable us to examine the events that occur in hypersensitivity lung disease in greater detail and should provide ideas for studying the human disease.

\section{ACKNOWLEDGMENTS}

The authors gratefully acknowledge the technical skills of Mary Scharpf, Patricia Sullivan, and Ellen Buchmann, the editorial assistance of Catherine Walther and Pat Welsch, and the preparation of the illustrations by Carole Russell Hilmer. We are also grateful to Dr. Quentin N. Myrvik for his suggestions and encouragement.

This research was supported by the Specialized Center of Research (SCOR) grant HL 15389 from the National Heart and Lung Institute.

\section{REFERENCES}

1. Fink, J. N., A. J. Sosman, J. J. Barboriak, D. P. Schlueter, and R. A. Holmes. 1968. Pigeon breeders' disease-a clinical study of a hypersensitivity pneumonitis. Ann. Intern. Med. 68: 1205-1219.

2. Fink, J. N., A. J. Sosman, J. E. Salvaggio, and J. J. Barboriak. 1971. Precipitins and the diagnosis of a hypersensitivity pneumonitis. J. Allergy Clin. Immunol. 48: 179-181.

3. Caldwell, J. R., D. E. Pearce, C. Spencer, R. Leder, and R. H. Waldman. 1973. Immunologic mechanisms in hypersensitivity pneumonitis. J. Allergy Clin. Immunol. 52: $225-230$.

Experimental Hypersensitivity Pneumonitis 
4. Moore, V. L., J. N. Fink, J. J. Barboriak, L. L. Ruff, and D. P. Schlueter. 1974. Immunologic events in pigeon breeders' disease. J. Alllergy Clin. Immunol. 53: 319328.

5. Hansen, P. J., and R. Penny. 1974. Pigeon-breeder's disease. Study of the cell-mediated immune response to pigeon antigens by the lymphocyte culture technique. Int. Arch. Allergy. Appl. Immunol. 47: 498-507.

6. Fink, J. N. 1974. Hypersensitivity pneumonitis: a case of mistaken identity. Hosp. Pract. March, 119-124.

7. Moore, V. L., and J. N. Fink. 1975. Immunologic studies in pigeon breeders' disease-quantitative precipitins and complement-fixing antibodies in symptomatic and asymptomatic pigeon breeders. J. Lab. Clin Med. 85: $540-545$.

8. Fink, J. N., T. Tebo, and J. J. Barboriak. 1969. Characterization of human precipitating antibody to inhaled antigens. J. Immunol. 103: 244-251.

9. Moore, V. L., and Q. N. Myrvik. 1973. Relationship of BCG-induced pulmonary delayed hypersensitivity to accelerated granuloma formation in rabbit lungs: effect of cortisone acetate. Infect. Immun. 7: 764-770.

10. Campbell, D. H., J. S. Garvey, N. E. Cremer, and D. H. Sussdorf. 1970. Methods in Immunology. W. A Benjamin, Inc., New York. 2nd edition. 454 pp.

11. Block, K. J., F. M. Kourilsky, Z. Ovary, and B. Benacerraf. 1963. Properties of guinea pig 7S antibodies. III. Identification of antibodies involved in complement fixation and hemolysis. J. Exp. Med. 117 : 965-981.

12. Myrvik, Q. N., E. S. Leake, and B. Fariss. 1961. Studies on pulmonary alveolar macrophages from the normal rabbit: a technique to procure them in a high state of purity. J. Immunol. 86: 128-132.

13. David, J. R. 1965. Suppression of delayed hypersensitivity in vitro by inhibition of protein synthesis. J. Exp. Med. 122: 1125-1134.

14. Moore, V. L., and S. L. Tobolski. 1974. A modified macro-method for the quantitation of the hemolytic activity of rabbit complement. J. Immunol. Methods. 5: 71-76.

15. Lutz, W. 1973. Statistical methods as applied to immunological data. In Handbook of Experimental Im- munology. D. M. Weir, editor. Blackwell Scientific Publications Ltd., Oxford, England. 2nd edition. A1-1A1-28.

16. Myrvik, Q. N., E. S. Leake, and S. Oshima. 1962. A study of macrophages and epithelioid-like cells from granulomatous (BCG-induced) lungs of rabbits. J. Immunol. 89: 745-751.

17. Benveniste, J., P. M. Henson, and C. G. Cochrane. 1972. Anaphylactic reactions and the deposition of circulating immune complexes. In Inflammation-Mechanisms and Control. I. H. Lepow and P. A. Ward, editors. Academic Press, Inc., New York. 179-193.

18. Hensley, G. T., J. C. Garancis, G. D. Cherayil, and J. N. Fink. 1969. Lung biopsies of pigeon breeders' disease. Arch. Pathol. 87: 572-579.

19. Emanuel, D. A., F. J. Wenzel, C. I. Bowerman, and B. R. Lawton. 1964. Farmer's lung-clinical, pathologic and immunologic study of twenty-four patients. $\mathrm{Am}$. J. Med. $37: 392-401$.

20. Ghose, T., P. Landrigan, R. Kileen, and J. Dill. 1974. Immunopathologic studies in patients with farmer's lung. Clin. Allergy. 4: 119-129.

21. Seal, R. M. E., E. J. Hapke, G. O. Thomas, J. C. Meek, and M. Hayes. 1968. The pathology of the acute and chronic stages of farmer's lung Thorax. 23: 469-489.

22. Miller, T. E., G. B. Mackaness, and P. H. Lagrange. 1973. Immunopotentiation of $\mathrm{BCG}$. II. Modulation of the response to sheep red blood cells. J. Natl. Cancer Inst. 51: 1669-1676.

23. Nielson, K. H., K. Parratt, G. Boyd, and R. G. White. 1974. Use of radiolabelled antiglobulin for quantitation of antibody to soluble antigens rendered particulate: application to human sera from 'Pigeon Fancier's Lung Syndrome.' Int. Arch. Allergy. 47: 339-350.

24. Fink, J. N., J. J. Barboriak, A. J. Sosman, R. F. Bukosky, and J. A. Arkins. 1968. Antibodies against pigeon serum proteins in pigeon breeders. J. Lab. Clin. Med. $71: 20-24$.

25. Uhr, J. W. 1966. Delayed hypersensitivity. Physiol. Rev. 46 : 359-417. 